Saudi Journal of Oral and Dental Research

Abbreviated Key Title: Saudi J Oral Dent Res

ISSN 2518-1300 (Print) |ISSN 2518-1297 (Online)

Scholars Middle East Publishers, Dubai, United Arab Emirates

Journal homepage: https://saudijournals.com

\title{
Dentine Hypersensitivity and Attrition among Young and Elderly Patients of Bruxism
}

\author{
Dania Fatima ${ }^{1}$, Saria Imtiaz ${ }^{1}$, Um-e-Farwa $^{1}$, Hareem Ahsan ${ }^{2}$, Amina Tariq $^{2 *}$ \\ ${ }^{1}$ de, Montmorency College of Dentistry, Lahore, Pakistan \\ ${ }^{2}$ University College of Medicine and Dentistry, University of Lahore, Pakistan
}

DOI: $\underline{10.36348 / \text { sjodr.2020.v05i12.009 }}$

| Received: 09.11.2020 | Accepted: 23.12.2020 | Published: 26.12 .2020

*Corresponding author: Amina Tariq

Abstract

This study aimed to explore the difference of teeth hypersensitivity and attrition among young and elderly patients of bruxism in Lahore. Data of 80 participants was collected using convenient sampling technique for this crossectional study. Chi-square test was used to explore the difference teeth hypersensitivity and attrition among young and elderly patients of bruxism. The results of chi-square revealed a significant difference of teeth hypersensitivity among young and elderly patients with bruxism $\left(\mathrm{X}^{2}=13.653, \mathrm{P}<.001\right)$. Among young patients with bruxism, $34 \%$ had teeth hypersensitivity as compared to the elderly patients with bruxism which were $66 \%$. Age wise significant difference was also found among patients of bruxism in terms of attrition $\left(\mathrm{X}^{2}=30.0, \mathrm{P}<.001\right)$. Tooth attrition was found in $12.5 \%$ young patients with bruxism whereas in elderly patients, $87.5 \%$ of the sample was having teeth attrition. In conclusion, the age wise difference of teeth attrition and teeth hypersensitivity among patients of bruxism was to be significantly different.

Keywords: Bruxism, Hypersensitivity, Attrition, dental patients.

Copyright (C) 2020 The Author(s): This is an open-access article distributed under the terms of the Creative Commons Attribution 4.0 International License (CC BY-NC 4.0) which permits unrestricted use, distribution, and reproduction in any medium for non-commercial use provided the original author and source are credited.

\section{INTRODUCTION}

In a sample from Canadian population, influence of dental as well as facial pain was analyzed by Locker and his colleague in 1987 for the first time. They associated dental pain with psychosocial factors in a systematic way [1]. Oral pain within last 4 weeks was reported by $39.7 \%$ patients among which $28.8 \%$ pain was due to hypersensitivity (pain due to the introduction of hot and cold fluid intake). About $50 \%$ of dental pain was correlated with psychological factors whereas $70 \%$ of the oral pain was found to be linked with behavioral factors. This study concluded that there is a positive relationship between dental pain and tooth sensitivity $[1,3]$. Dentofacial pain could be attributed to hypersensitivity due to dentin exposure for many reasons such as teeth grinding or bruxism $[2,4,5]$.

Contrary to the deep-rooted research in the caries epidemiology, very limited data is available on teeth hypersensitivity due to bruxism among young and elderly patients. Hence, this study aimed to explore the difference of teeth hypersensitivity and attrition among young and elderly patients of bruxism in Lahore.

\section{METHODOLOGY \\ Research design: Crossectional research}

Sampling technique: Convenient sampling

Sample Size: 80 patients were taken as the sample of the study from which 40 patients were between age ranges from 18-30years and 40 patients were between age ranges from $40-60$ years.

\section{Procedure}

With the permission of Medical superintendent of Punjab dental hospital, data collection was done. The aim of the study was explained to the patients before data collection and informed consent was taken from each patient. Presence or absence of bruxism was recorded as well as sensitivity test was conducted for data collection. Teeth attrition was also observed and recorded.

\section{Data Analysis}

Data was analyzed using SPSS version 20.0. Chi-Square test was used to explore the prevalence of bruxism, sensitivity and teeth attrition in young and elderly population. 


\section{RESULTS}

The results of chi-square revealed a significant difference of teeth hypersensitivity among young and elderly patients with bruxism $\left(\mathrm{X}^{2}=13.653, \mathrm{P}<.001\right)$.
Among young patients with bruxism, 34\% had teeth hypersensitivity as compared to the elderly patients with bruxism which were $66 \%$.

Table-1: Age wise comparison of teeth hypersensitivity in dental patients with bruxism

\begin{tabular}{|c|c|c|c|}
\hline & \multicolumn{2}{|c|}{ Teeth Hypersensitivity } \\
\hline & & Yes & No \\
\hline \multirow[t]{3}{*}{ Age Group } & Young Patients (18-30years) & $34.0 \%$ & $76.7 \%$ \\
\hline & Elderly Patients (40-60years) & $66.0 \%$ & $23.3 \%$ \\
\hline & \multicolumn{3}{|l|}{$X^{2}=13.653, P<.001$} \\
\hline
\end{tabular}

Age wise significant difference was also found among patients of bruxism in terms of attrition $\left(\mathrm{X}^{2}=\right.$ $30.0, \mathrm{P}<.001)$. Tooth attrition was found in $12.5 \%$ young patients with bruxism whereas in elderly patients, $87.5 \%$ of the sample was having teeth attrition.

Table-2: Age wise comparison of teeth attrition in dental patients with bruxism

\begin{tabular}{|l|l|l|l|}
\hline \multicolumn{2}{|c|}{} & \multicolumn{2}{|l|}{ Attrition } \\
\cline { 3 - 4 } Age Group & Young Patients (18-30years) & $12.5 \%$ & $75.0 \%$ \\
\cline { 2 - 4 } & Elderly Patients (40-60years) & $87.5 \%$ & $25.0 \%$ \\
\cline { 2 - 4 } & $\mathbf{X}^{2}=\mathbf{3 0 . 0}, \mathbf{P}<.001$ & \multicolumn{2}{|l}{} \\
\hline
\end{tabular}

\section{DISCUSSION}

The aim of the study was to explore the age wise difference of teeth attrition and teeth hypersensitivity among patients of bruxism which was to be significantly different.

According to the finding of current study, among young patients of bruxism, 34\% patients face hypersensitivity of teeth whereas in elderly patients, increased percent of patients came with complaint of teeth hypersensitivity $(66 \%)$. Dentine hypersensitivity was found among $55 \%$ of the patients in Europe which is less than the teeth hypersensitivity explored in current study results among elderly patients. ${ }^{6}$ The results of another study conducted in UK showed the prevalence of dentine hypersensitivity among elderly patients was $2.8 \%$ which was very much less as compared to the results of current study [7].

Furthermore, the findings of the study with regards to the teeth attrition was found higher among elderly patients $(87.5 \%)$ as compared to the young patients with bruxism (12.5\%). $57 \%$ of dental patients were found of having attrition which was lower than the results of present study [8].

In conclusion, the age wise difference of teeth attrition and teeth hypersensitivity among patients of bruxism was to be significantly different.

Conflict of Interest: No conflict of interest.

\section{REFERENCES}

1. Locker, D., \& Grushka, M. (1987). The impact of dental and facial pain. Journal of dental Research, 66(9), 1414-1417.

2. Holland, G., Narhi, M. N., Addy, M., Gangarosa, L., \& Orchardson, R. (1997). Guidelines for the design and conduct of clinical trials on dentine hypersensitivity. Journal of clinical periodontology, 24(11), 808-813.

3. Addy, M. (1990). Etiology and clinical implications of dentine hypersensitivity. Dental Clinics of North America, 34(3), 503-514.

4. Chabanski, M. B., \& Gillam, D. G. (1997). Aetiology, prevalence and clinical features of cervical dentine sensitivity. Journal of oral rehabilitation, 24(1), 15-19.

5. Goldberg, M., Grootveld, M., \& Lynch, E. (2010). Undesirable and adverse effects of tooth-whitening products: a review. Clinical oral investigations, 14(1), 1-10.

6. Olley, R. C., Wilson, R., Moazzez, R., \& Bartlett, D. (2013). Validation of a Cumulative Hypersensitivity Index (CHI) for dentine hypersensitivity severity. Journal of Clinical Periodontology, 40(10), 942-947.

7. Rees, J. S., \& Addy, M. (2004). A cross- sectional study of buccal cervical sensitivity in UK general dental practice and a summary review of prevalence studies. International journal of dental hygiene, 2(2), 64-69.

8. Bartlett, D. W., Lussi, A., West, N. X., Bouchard, P., Sanz, M., \& Bourgeois, D. (2013). Prevalence of tooth wear on buccal and lingual surfaces and possible risk factors in young European adults. Journal of dentistry, 41(11), 1007-1013. 